\title{
Efficacy and safety of pregabalin in elderly people with generalised anxiety disorder*
}

\author{
Stuart Montgomery, Krai Chatamra, Lynne Pauer, Ed Whalen and Francesca Baldinetti
}

\section{Background}

Pregabalin is a novel compound that has been shown to have efficacy in the treatment of generalised anxiety disorder and is licensed for the treatment of the disorder in the European Union.

\section{Aims}

The current study was designed to evaluate the safety and efficacy of pregabalin, an $\alpha_{2} \delta$-ligand, in the treatment of generalised anxiety disorder in people 65 years and older

\section{Method}

This was a double-blind, randomised (2:1), placebocontrolled, 8-week trial of pregabalin, in flexible doses of 150-600 mg/day, in the treatment of DSM-IV generalised anxiety disorder with a baseline Hamilton Rating Scale for Anxiety (HRSA) total score $\geqslant 20$. The primary outcome was end-point (week 8 or last visit, with last observation carried forward (LOCF)) change in HRSA total score.

\section{Results}

A total of 273 patients (women, 78\%; mean age, 72 years $(s . d .=6)$; mean baseline HRSA total score, $26(s . d .=4.6))$ were randomised and received study treatment. On the primary intent-to-treat LOCF analysis, pregabalin was associated with a 2-point greater reduction in HRSA total score than placebo (12.87 v. 10.7; $P<0.05$ ). In a post hoc repeated measures mixed-effect model analysis, pregabalin was associated with significantly greater improvement than placebo in the HRSA total score from week $2(-9.8$ (s.d.=0.6) v. -7.2 (s.d. $=0.8)$; $P=0.0052)$ through week $8(-14.4(s . d .=0.6) v .-11.6$ (s.d. $=0.8) ; P=0.0070)$. Significant improvement was observed in the pregabalin group on both the HRSA psychic and somatic anxiety factors. There was a significantly greater decrease from baseline in mean Hamilton Rating Scale for Depression (HRSD) score with pregabalin compared with placebo ( -5.48 (s.d. $=0.46)$ v. -4.02 (s.d. $=0.59) ; P=0.041$ ). Pregabalin was well-tolerated, with almost all adverse events in the mild-to-moderate range, and self-limiting (median duration of 4-16 days). Discontinuations due to adverse events were similar for pregabalin $(10.7 \%)$ and placebo (9.4\%).

\section{Conclusions}

Pregabalin, in doses of 150-600 mg/day, was a safe and effective treatment of generalised anxiety disorder in patients 65 years and older. The anxiolytic efficacy of pregabalin had an early onset (by 2 weeks) and significantly improved both psychic and somatic symptoms of anxiety.

\section{Declaration of interest}

This study was sponsored by Pfizer Inc. S.M. has served on advisory boards for Pfizer, has received fees as a consultant to Pfizer, and has been reimbursed for travel-related expenses incurred for scientific meetings. K.C., L.P., E.W. and F.B. are full-time employees of Pfizer.
Generalised anxiety disorder is a common disorder in the elderly, with 1-6 month prevalence estimates in the community ranging from 2 to $7 \% .^{1-3}$ In primary care, prevalence rates are even higher. ${ }^{4,5}$

Unlike other anxiety disorders which have an overwhelmingly early age at onset, the age at onset of generalised anxiety disorder appears to be after 40 years in about a third of individuals, with up to $10 \%$ of cases having a first onset after the age of $50 .{ }^{6}$ Generalised anxiety disorder appears to be most common in older age groups, ${ }^{7}$ steadily rises until age 50 , and may be the most common anxiety disorder in adults aged 55 and over. ${ }^{8}$

In younger adults, prospective studies have found that generalised anxiety disorder has notably higher chronicity than major depression, with remission rates at 12 years of approximately $42 \% .{ }^{9}$ In older adults it also appears to be chronic, with 6-year remission rates of $31 \% .^{10}$

Generalised anxiety disorder in the elderly is frequently comorbid with both major depression (in 30-90\% of cases) and with physical illnesses. ${ }^{8,11}$ Risk factors for generalised anxiety disorder in the elderly, based on a multivariate analysis in a community-based sample, include increased life stressors or recent losses, increased illness burden and related functional limitations, and absence of social support. ${ }^{2}$

*Presented in part at the 159th Annual Meeting of the American Psychiatric Association, Toronto, Canada, 20-25 May 2006.
Across all age groups, the presence of generalised anxiety disorder has been found to be associated with a more than 8 -fold increase in the annual utilisation of both out-patient medical and psychiatric services. ${ }^{5}$ In elderly people with the disorder, utilisation of healthcare services continues to be significantly elevated, though relatively few are treated outside primary care settings.

In the past 25 years, only one small ( $n=17$ per treatment group) placebo-controlled study has been reported that evaluated the efficacy of pharmacological treatment of DSM-III/IV generalised anxiety disorder in the elderly. ${ }^{12}$ This study reported significant anxiolytic benefit for citalopram. A second analysis of pooled data $(n=195)$ from five adult generalised anxiety disorder trials found improvement in an elderly subgroup (mean age 65 years) after 8 weeks of treatment with venlafaxine extended release, but the degree of improvement was not significantly better than with placebo. ${ }^{13}$ Benzodiazepines continue to be the predominant treatment of generalised anxiety disorder in the elderly, despite the absence of specific evidence for efficacy in this population and the associated risks, including cognitive, memory and psychomotor impairment, and risk of injury due to falling. ${ }^{14}$

Pregabalin is a novel compound that has been shown to have efficacy in the treatment of generalised anxiety disorder. ${ }^{15-18}$

The objective of the current study was to evaluate the efficacy and safety of pregabalin in elderly out-patients diagnosed with generalised anxiety disorder. 


\section{Method}

\section{Study design}

This was a randomised (2:1 pregabalin:placebo), double-blind, placebo-controlled, 8-week parallel group comparison following a 1-week drug-free screening period. At study end, treatment was discontinued during a double-blind, 1-5 day taper, with a final follow-up visit at 1 week.

Pregabalin treatment was initiated at $50 \mathrm{mg} /$ day, followed by an increase to $100 \mathrm{mg}$ /day on day 3, and $150 \mathrm{mg} /$ day on day 5. Dosing was flexible from weeks 1 to 6 in the range of $150-600 \mathrm{mg} / \mathrm{day}$, administered either twice daily or three times daily. Patients were maintained on the same dose of medication from weeks 6 to 8 .

The study was conducted at 13 US and 69 European centres in accordance with the Declaration of Helsinki and Good Clinical Practice guidelines. ${ }^{19}$ The protocol was approved at each centre by the appropriate ethics panel, and written informed consent was obtained from each patient prior to enrolment. Patients were recruited through clinic referrals and by ethics panel-approved advertisements in local media.

\section{Participant selection}

Male or female out-patients aged 65 years or older, who met DSM-IV ${ }^{20}$ criteria for generalised anxiety disorder based on a structured Mini International Neuropsychiatric Interview (MINI), ${ }^{21,22}$ who had screening and baseline Hamilton Rating Scale for Anxiety (HRSA) ${ }^{23}$ scores $\geqslant 20$ and a Mini-Mental State Examination (MMSE) score $\geqslant 24$, were eligible for entry. Patients were excluded if they met any of the following criteria:

(a) current or past DSM-IV diagnosis of schizophrenia, schizoaffective, psychotic, or bipolar disorder

(b) current DSM-IV diagnosis of major depressive disorder, social anxiety disorder (generalised type), panic disorder, obsessivecompulsive disorder, post-traumatic stress disorder or acute stress disorder, borderline or antisocial personality disorder, eating disorder, delirium, dementia, amnestic disorder, alcohol or substance dependence and/or misuse (in the past 6 months)

(c) positive urine drug screen

(d) any clinically significant acute or unstable medical condition (including current seizure disorder, even if stable on treatment) or clinically significant electrocardiogram (ECG) or laboratory abnormalities

(e) alanine/aspartate aminotransferase levels $>3$ times the upper limit of normal or creatinine clearance rates $\leqslant 45 \mathrm{ml} / \mathrm{min}$

(f) concurrent psychotherapy for generalised anxiety disorder, unless in stable treatment for $>3$ months

(g) concomitant treatment with psychotropic medication during the study and for at least 2 weeks prior to the screening visit (5 weeks for fluoxetine)

(h) current suicide risk, based on the clinical judgement of the investigator

(i) depressive symptoms predominating over anxiety symptoms. Medical evaluation, physical examination, electrocardiogram (ECG), laboratory data and pregnancy test were carried out at screening.

\section{Efficacy measures}

The primary efficacy measure was the change from baseline to end-point (week 8 or last observation carried forward (LOCF) in double-blind phase) in the 14-item, clinician-rated HRSA. The HRSA was performed at screening, baseline and weeks 1, 2, $4,6,8$ (or at the time of early discontinuation), and at week 9 (the post-taper follow-up visit). The original HRSA has shown acceptable internal consistency and construct validity in elderly people with generalised anxiety disorder. ${ }^{24}$

Secondary efficacy measures were:

(a) 17-item Hamilton Rating Scale for Depression (HRSD-17), ${ }^{25}$ completed at baseline and week 8 (or early termination)

(b) the Clinical Global Impression - Improvement Scale (CGI-I), ${ }^{26}$ completed at weeks $1,2,4,6$, and 8 (or early termination)

(c) the Symptom Checklist-90, revised (SCL-90-R), ${ }^{27}$ completed at baseline and week 8 (or early termination)

(d) the MMSE, completed at baseline, week 8 (or early termination), and at the week 9 post-taper visit.

The following derived outcomes were also analysed:

(a) HRSA psychic anxiety factor (items 1-6, 14)

(b) HRSA somatic anxiety factor (items 7-13)

(c) individual HRSA anxiety (item 1) and tension (item 2) items

(d) the SCL-90-R anxiety sub-scale (consisting of 8 items)

(e) responder criteria (defined as CGI-I $\leqslant 2$ 'much' or 'very much' improved, and $\geqslant 50 \%$ reduction from baseline in the HRSA total score)

(f) HRSA remission criteria (HRSA $\leqslant 7$ ). A repeated-measures analysis was also performed on the HRSA and CGI-I scales.

Experienced raters were used and rater training was provided. Linguistically validated versions of efficacy measures were administered in the native language of the study patient.

\section{Safety and tolerability measures}

Spontaneously reported or observed adverse events were recorded with regard to onset, duration and severity. Adherence was monitored by counts of returned medication, and patients were counselled if they were found to be non-adherent. Vital signs were obtained at each visit. The ECG, physical examination, and laboratory testing were repeated at week 8 (or early termination).

\section{Statistical methods}

As preferred by regulatory bodies, the primary efficacy analysis, which compared the HRSA change scores at end-point, was carried out at end-point on the intent-to-treat population (all randomised patients who received at least one dose of study medication) using the LOCF for missing values. All statistical analyses were performed using SAS statistical package (Version 8) for Windows. A sample size of 261 evaluable patients per treatment group would provide $80 \%$ power to detect a mean difference of 3.0 with a standard deviation of 8.1 in the HRSA score between placebo and pregabalin with an experiment-wise $\alpha$-level of 0.05 . The HRSA change score was also analysed using an analysis of covariance (ANCOVA) model that included the effects of treatment and centre, with baseline HRSA total score as a covariate. ${ }^{28}$ Least-squares means and $95 \%$ confidence intervals were calculated. Weekly HRSA change scores were analysed separately at each week by ANCOVA using a model that included the effects of treatment and centre, with baseline HRSA total score as a covariate.

The treatment effects of pregabalin on the HRSA psychic and somatic sub-scales, and on HRSA items 1 and 2, were evaluated by ANCOVA analyses. The HRSD change scores were analysed using 
ANCOVA with treatment and centre in the model, and HRSD score at baseline as the covariate ( $\alpha=0.05$, two-sided).

Logistic regression adjusting for centre was performed to compare the percentage of HRSA responders/remitters by treatment group in the intent-to-treat population ( $\alpha=0.05$, two-sided). ${ }^{29,30}$ Odds ratios and $95 \%$ confidence intervals for pregabalin relative to placebo were computed. The CGI-I responder rates were analysed in the same manner as the HRSA responder rates.

A secondary post hoc mixed-model repeated-measures analysis, which is increasingly recommended as an alternative method to assess the impact of missing data, was carried out. No adjustment for multiple comparisons of the secondary measures was made as these are usually regarded as exploratory.

\section{Results}

\section{Participant characteristics and disposition}

Of the 366 patients screened, 273 were randomised and received study treatment (Fig. 1). There were no significant between-group differences in baseline demographic or clinical characteristics (Table 1). A similar proportion of participants in the pregabalin and placebo groups $(75.1 \%$ v. $71.9 \%)$ completed double-blind study treatment (Fig. 1). Reasons for premature discontinuation were approximately similar in both treatment groups.

\section{Efficacy}

On the primary outcome, change from baseline to end-point LOCF in HRSA total score, treatment with pregabalin was significantly superior to placebo: pregabalin $-12.8($ s.d. $=0.7)$; placebo -10.7 (s.d.=0.9); $P=0.044$. Additionally, from week 2 through the end of double-blind treatment, pregabalin showed statistically significant greater changes in HRSA score compared with placebo patients (Fig. 2 and Table 2; a more detailed version of Table 2, showing results from baseline to end-point, appears as online Table DS1).

There was a significant advantage for pregabalin compared with placebo from week 2 onwards on the HRSA psychic anxiety factor and from week 4 onwards on the HRSA somatic anxiety factor (Fig. 3 and Table DS1). There was a significantly greater improvement on the CGI-I with pregabalin compared with placebo (Table DS1).

There were significantly more responders (HRSA $\geqslant 50 \%$ reduction from baseline) on pregabalin compared with placebo at week 4 but not at week 8 on either a completer or LOCF analysis (Fig. 4). There was no significant difference at end-point in responders on the CGI-I ('much'/'very much improved': $58.4 \%$ v. $48.4 \% ; P=0.117)$. There was no significant difference in remission rates (HRSA $\leqslant 7: 29.8 \%$ v. $24.2 \% ; P=0.368$ ).

An ANCOVA of patient-rated anxiety was consistent with the investigator-rated HRSA: there was significantly greater improvement on the SCL-90-R anxiety sub-scale least-squares mean change score at end-point for pregabalin compared with placebo $(-5.6$ (s.d. $=0.4)$ v. -4.2 (s.d. $=0.5) ; P=0.0412)$. There was no difference in end-point change on the SCL-90-R total score with pregabalin compared with placebo $(-29.7($ s.d.=2.7) $v . \quad-27.9$ (s.d.=3.5); $P=0.6574$ )

An ANCOVA of secondary baseline depressive symptoms (mean HRSD-17=14 (s.d.=3.6) found significantly greater improvement at end-point for pregabalin compared with placebo $(-5.5$ (s.d.=0.5) v. -4.0 (s.d.=0.6); $P=0.0414)$.

\section{Efficacy in clinically relevant subgroups}

To address the regulatory request for information on efficacy in patients with more severe generalised anxiety disorder, a post

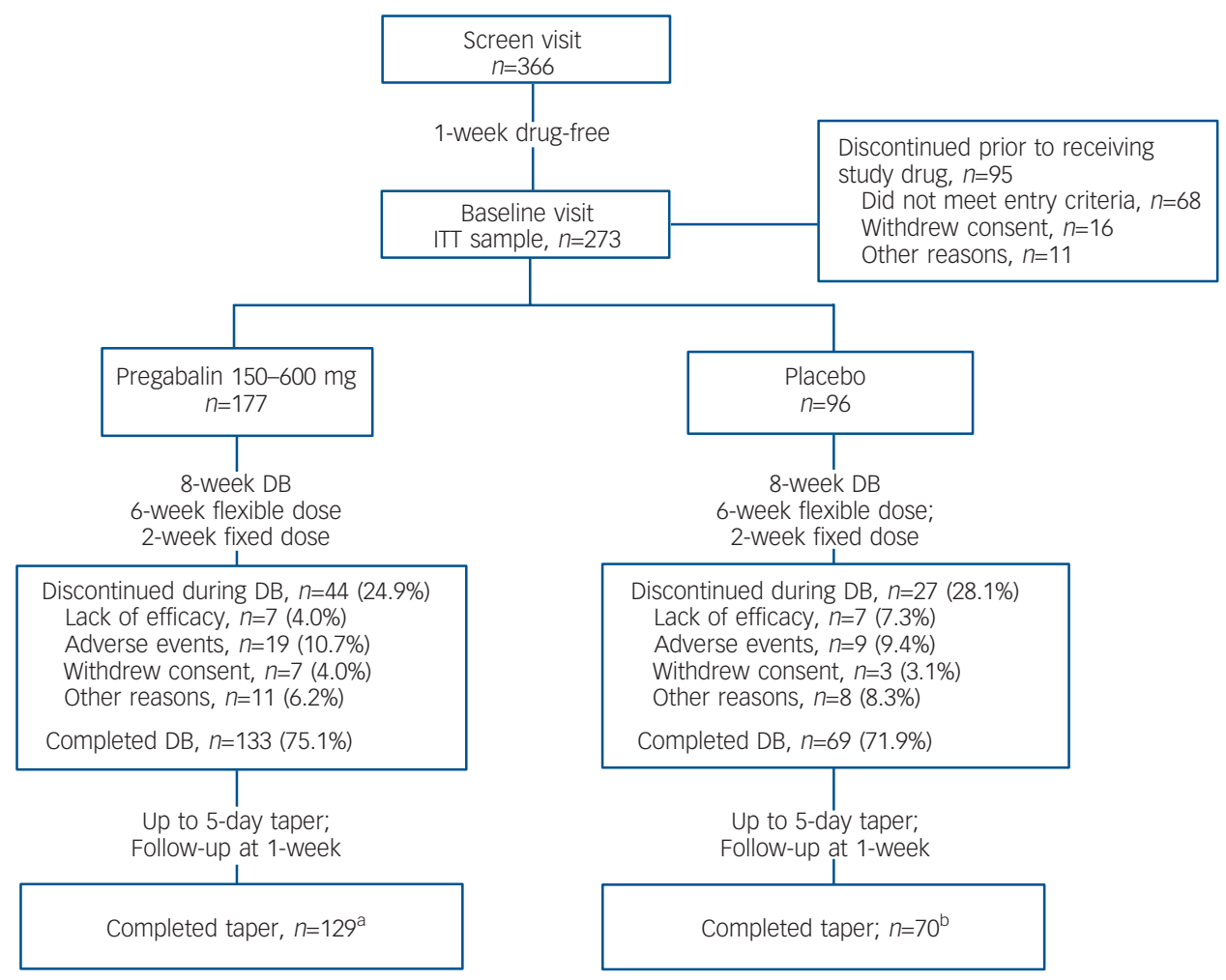

Fig. 1 Flow diagram of participants through study.

$\mathrm{DB}$, double-blind; ITT, intent-to-treat.

a. Did not enter taper phase because of dosing error $(n=1)$, non-adherence $(n=1)$, and administrative reasons $(n=2)$.

b. Patients who did not complete the 8 weeks of double-blind treatment could nevertheless enter taper phase. 


\begin{tabular}{|c|c|c|}
\hline & $\begin{array}{c}\text { Pregabalin } \\
n=177\end{array}$ & $\begin{array}{c}\text { Placebo } \\
n=96\end{array}$ \\
\hline Female, \% & 79 & 75 \\
\hline $\begin{array}{l}\text { Age, years } \\
\quad \text { Mean (s.d.) } \\
\geqslant 75 \text { years, } \%\end{array}$ & $\begin{array}{c}72.4(5.6) \\
35\end{array}$ & $\begin{array}{c}72.2(6.4) \\
32\end{array}$ \\
\hline White, \% & 98 & 99 \\
\hline Weight, kg: mean (s.d.) & 70.7 (12.2) & $74.4(17.2)$ \\
\hline $\begin{array}{l}\text { Generalised anxiety disorder history } \\
\text { Estimated age at onset, years: mean (s.d.) } \\
\text { Estimated number of prior episodes, } \\
\text { mean (s.d.) } \\
\text { Duration of current episode, months: } \\
\text { mean (s.d.) }\end{array}$ & $\begin{array}{l}56(17) \\
3(3.7) \\
16(30)\end{array}$ & $\begin{array}{l}56(17) \\
4(5.9) \\
14(25)\end{array}$ \\
\hline $\begin{array}{l}\text { Previous psychiatric diagnoses, \% } \\
\text { Major depression } \\
\text { Dysthymic disorder or depression NOS } \\
\text { Other anxiety disorder }\end{array}$ & $\begin{array}{r}11.3 \\
12.4 \\
1.7 \\
\end{array}$ & $\begin{array}{r}12.5 \\
9.4 \\
4.2\end{array}$ \\
\hline $\begin{array}{l}\text { HRSA, mean (s.d.) } \\
\text { Total score } \\
\text { Psychic factor score } \\
\text { Somatic factor score }\end{array}$ & $\begin{array}{c}27(4.8) \\
14.3(2.9) \\
12.3(3.1) \\
\end{array}$ & $\begin{array}{c}26(4.1) \\
14.2(2.4) \\
11.9(3.1) \\
\end{array}$ \\
\hline HRSD-17, mean (s.d.) & $14(3.7)$ & $14(3.5)$ \\
\hline MMSE, mean (s.e.) & $28.3(0.1)$ & $28.3(0.2)$ \\
\hline
\end{tabular}

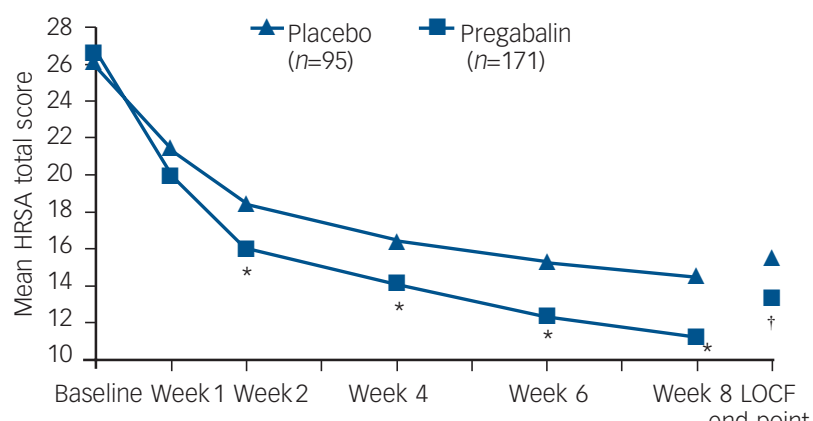

Fig. 2 Mean HRSA total score over 8 weeks of study treatment.

HRSA, Hamilton Rating Scale for Anxiety; LOCF end-point, last-observation carried forward ANCOVA model.

Weeks 1-8 $P$-values based on a repeated-measures mixed-effect model.

${ }^{*} P<0.01 ;{ }^{\dagger} P=0.0437$.

hoc analysis was carried out in the subgroup of participants with high anxiety severity, defined as a baseline HRSA total score $\geqslant 26$. The magnitude of improvement (least-squares mean change score at 8-week end-point) was numerically greater for pregabalin compared with placebo $(-15.4$ (s.e. $=1.0)$ v. -12.7 (s.e. $=1.4)$; $P<0.096$ ). A comparison of effect sizes (pregabalin $v$. placebo at end-point) showed comparable benefit as the severity of baseline HRSA total scores increased from HRSA $\geqslant 20$ (Cohen's $d=0.26)$, to $\geqslant 22(d=0.28)$, to $\geqslant 24(d=0.32)$, to $\geqslant 26(d=0.30)$, to $\geqslant 28(d=0.33)$.

The influence of baseline severity of depressive symptoms was also examined. The magnitude of end-point improvement in the HRSA total score for pregabalin was similar in participants with high $v$. low levels of subsyndromal depression at baseline (HRSD $\geqslant 15$ v. $\operatorname{HRSD}<15$ : -12.5 (s.d.=1.1) v. -13.0 (s.d.=0.9)), a
HRSA psychic

HRSA somatic

Week 4 Week 8

Week $4 \quad$ Week 8
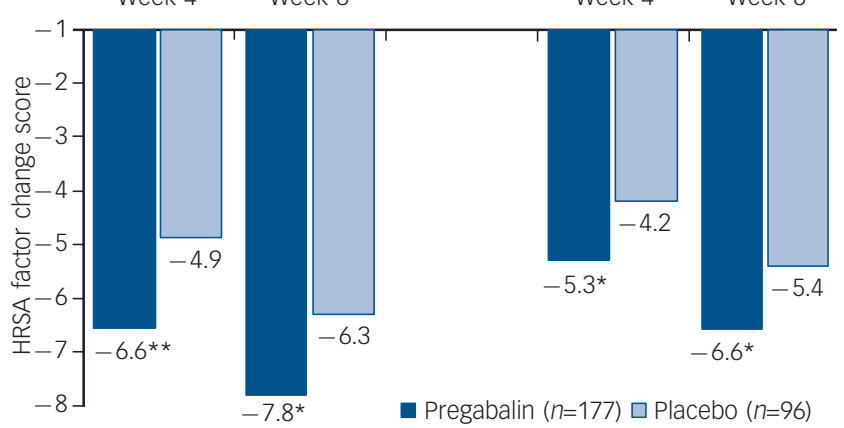

- Pregabalin $(n=177) \square$ Placebo $(n=96)$

Fig. 3 Mean change in HRSA psychic and somatic factor scores: results of mixed-model repeated-measures analysis.

HRSA, Hamilton Rating Scale for Anxiety.

${ }^{*} P<0.05 ; * * P<0.01$

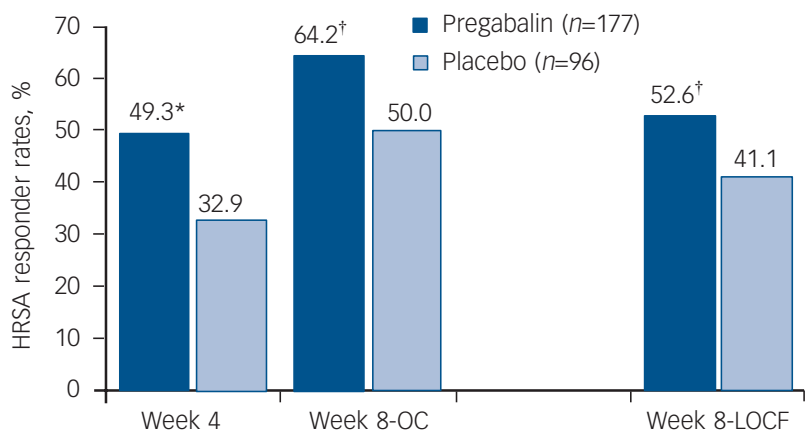

Fig. 4 Mean HRSA responder rates at 4 weeks and 8 weeks.

HRSA, Hamilton Rating Scale for Anxiety; OC, observed case; LOCF, last observation carried forward.

${ }^{*} P<0.05 ;{ }^{\dagger} P \leqslant 0.07$

finding mirrored in those on placebo $(-11.0 \quad$ (s.d.=1.4) $v$. -10.3 (s.d.=1.2)).

\section{Tolerability and safety}

Pregabalin was well-tolerated on a mean maximal dose of $270 \mathrm{mg} /$ day (s.d.=145). The great majority of adverse events were mild to moderate in intensity and transient, with tolerance typically developing within the first 1-3 weeks of treatment (Table 3). Discontinuations due to adverse events were similar for pregabalin and placebo $(10.7 \%$ v. 9.4\%). The mean change in weight at endpoint was slightly higher for pregabalin $(+0.8 \mathrm{~kg}(\mathrm{~s} . \mathrm{d} .=2.5))$ compared with placebo $(-0.2 \mathrm{~kg}($ s.d. $=2.5))$.

Serious adverse events occurred in nine patients during study treatment, three $(3.1 \%)$ on placebo and seven $(4.0 \%)$ on pregabalin (two serious events occurred in one patient on pregabalin: an ulcer of the toe, and progression of chronic arteritis). One death due to cerebral haemorrhage occurred in an 82-year-old woman (this was judged by the investigator as not related to pregabalin). Three of the serious adverse events in patients on pregabalin were judged by the investigator to be related to pregabalin: increased anxiety, somnolence, and a fractured arm secondary to a fall. There was no difference in the incidence of treatment-emergent changes in ECG or laboratory tests for pregabalin compared with placebo. 
Table 2 Efficacy variables: results of repeated measures and LOCF end-point analyses

\begin{tabular}{|c|c|c|c|c|c|}
\hline \multirow[b]{2}{*}{ Efficacy variables } & \multicolumn{2}{|r|}{ Pregabalin } & \multicolumn{2}{|r|}{ Placebo } & \multirow[b]{2}{*}{$P^{\mathrm{a}}$} \\
\hline & $n$ & LS mean change (s.e.) & $n$ & LS mean change (s.e.) & \\
\hline \multicolumn{6}{|l|}{ HRSA total score } \\
\hline Week 8 & 120 & $-14.4(0.6)$ & 62 & $-11.6(0.8)$ & 0.0070 \\
\hline LOCF end-point & 171 & $-12.8(0.7)$ & 95 & $-10.7(0.9)$ & 0.0437 \\
\hline \multicolumn{6}{|l|}{ HRSA psychic factor } \\
\hline Week 8 & 120 & $-7.8(0.4)$ & 62 & $-6.3(0.5)$ & 0.0111 \\
\hline LOCF end-point & 171 & $-7.0(0.4)$ & 95 & $-5.6(0.5)$ & 0.0242 \\
\hline \multicolumn{6}{|l|}{ HRSA somatic factor } \\
\hline Week 8 & 120 & $-6.6(0.3)$ & 62 & $-5.4(0.5)$ & 0.0248 \\
\hline LOCF end-point & 171 & $-5.9(0.3)$ & 95 & $-5.0(0.4)$ & 0.0956 \\
\hline \multicolumn{6}{|l|}{ CGI-I } \\
\hline Week 8 & 121 & $2.3(0.1)$ & 62 & $2.7(0.1)$ & 0.0075 \\
\hline LOCF end-point & 171 & $2.5(0.1)$ & 95 & $2.8(0.1)$ & 0.0382 \\
\hline
\end{tabular}

Table 3 Treatment-emergent adverse events (all causes, with pregabalin incidence $\geqslant 5 \%$ )

\begin{tabular}{|c|c|c|c|c|c|c|}
\hline \multirow[b]{2}{*}{ Adverse event } & \multicolumn{3}{|c|}{ Pregabalin, $n=177$} & \multicolumn{3}{|c|}{ Placebo, $n=96$} \\
\hline & $\begin{array}{c}\text { Total incidence } \\
\text { (severe), \% }\end{array}$ & $\begin{array}{c}\text { Onset, }^{a} \\
\text { day }\end{array}$ & $\begin{array}{l}\text { Duration, }^{a} \\
\text { days }\end{array}$ & $\begin{array}{c}\text { Total incidence } \\
\text { (severe), \% }\end{array}$ & $\begin{array}{c}\text { Onset, }^{a} \\
\text { day }\end{array}$ & $\begin{array}{l}\text { Duration, }^{a} \\
\text { days }\end{array}$ \\
\hline Dizziness & $20.3(1.1)$ & 5.5 & 8 & $11.5(0)$ & 10 & 6 \\
\hline Somnolence & $13.0(0)$ & 4 & 16 & $7.3(0)$ & 5 & 14 \\
\hline Headache & $10.2(0)$ & 10 & 3.5 & $8.3(2.1)$ & 22.5 & 3 \\
\hline Nausea & $9.0(0.6)$ & 26.5 & 6 & $6.3(1.0)$ & 9 & 7 \\
\hline Infection & $5.6(0)$ & 24.5 & 10 & $3.1(0)$ & 7 & 7 \\
\hline
\end{tabular}

During rapid taper, the incidence of discontinuation-emergent adverse events was very low for pregabalin and placebo, respectively: dizziness $0.6 \%$ v. $0 \%$; insomnia $0.6 \%$ v. $0 \%$; pruritus $0 \%$ v. $1.0 \%$; and peripheral oedema $0 \%$ v. $1.0 \%$.

\section{Discussion}

The results of the protocolled intent-to-treat LOCF analysis demonstrate that pregabalin is effective in the treatment of generalised anxiety disorder in adults aged 65 and older. Pregabalin treatment was associated with significant improvement on the HRSA total score from week 2 through to end-point. About $50 \%$ of patients on pregabalin met HRSA responder criteria at week 4 , which increased to $64 \%$ by week 8 , although only the week- 4 response rate was significant compared with placebo.

Treatment with pregabalin resulted in significant improvement in both psychic and somatic symptoms of anxiety. The broad-spectrum improvement in both psychic and somatic symptoms is consistent with data from studies in younger adults and contrasts with selective serotonin reuptake inhibitor and serotonin-noradrenaline reuptake inhibitor anxiolytics, which do not always reduce somatic anxiety symptoms.

Patients in the current study reported a relatively late first onset of generalised anxiety disorder, at a mean age of 56 years. Although this is consistent with emerging epidemiological data, ${ }^{6}$ which suggest that generalised anxiety disorder may frequently begin after age 50, the reliability of retrospective assessment of age at onset is uncertain. Future studies are needed to evaluate whether early- $v$. late-onset generalised anxiety disorder have different presentations or a different course of illness or treatment response.

In the current sample, approximately $50 \%$ of participants presented with severe anxiety, defined as a minimum HRSA score of 26 at baseline. Treatment with pregabalin was comparably effective regardless of baseline anxiety severity, with effect sizes that showed a marginal increase (from 0.26 to 0.33 ) as baseline anxiety severity increased. Similarly, pregabalin was equally effective in the subgroup ( $40 \%)$ of patients who reported higher baseline levels of depressive symptoms (HRSD $\geqslant 15$ ).

The end-point difference in the HRSA total score $(<3$ points) is in line with the difference from placebo reported with other recently licensed treatments for generalised anxiety disorder, such as escitalopram and venlafaxine. ${ }^{31}$ Although these differences might appear modest, they are clinically relevant and have been used to justify the licensing of treatments for generalised anxiety disorder . This is the first large, placebo-controlled pharmacological treatment study in elderly people with generalised anxiety disorder and it is reassuring to have convincing evidence of the efficacy of a treatment for adults of all ages.

Pregabalin was well-tolerated at a mean dose of $270 \mathrm{mg} /$ day (s.d.=145). The proportion of patients who discontinued because of poor tolerability was similar for pregabalin and placebo $(\sim 10 \%)$. Severe adverse events for pregabalin were rare, occurring with a frequency above $1 \%$ only for dizziness $(2.1 \%)$. Tolerance rapidly developed to most adverse events, with a median duration in the range of 4-16 days. No unexpected safety events were noted on ECG or laboratory tests. During rapid taper, the incidence of discontinuation-emergent adverse events was the same for pregabalin and placebo. 


\section{Limitations}

The current study has several limitations. Study entry criteria excluded patients with comorbid major depression and/or other Axis I anxiety disorders, which reduces the generalisability of the results to clinical practice, where such comorbidity is relatively common. Future research is needed to evaluate the efficacy of pregabalin monotherapy in generalised anxiety disorder presenting with comorbid affective and anxiety disorders. The exclusion of more severe medical illness and psychiatric comorbidity is required in all pivotal studies seeking evidence for a licence for treatment in generalised anxiety disorder in order that the therapeutic benefit observed may be attributable to the effect on generalised anxiety disorder alone. However, the exclusion of patients with comorbid conditions is a limitation and future research is needed to establish the safety of pregabalin in elderly patients with more severe medical comorbidity. In light of the chronicity of generalised anxiety disorder, the current study is limited by the relatively short duration. A final limitation is the use of nominal $P$-values, unadjusted for multiple comparisons, for secondary efficacy measures. However, the study was designed for the analysis of the primary efficacy measure; the secondary analyses are usually regarded as exploratory. We consider the consistency of the findings with the secondary measures to be reassuring in supporting the efficacy demonstrated with the primary measure.

In conclusion, this study demonstrates that pregabalin, in a dosing range of $150-600 \mathrm{mg} /$ day, is a safe and effective treatment of generalised anxiety disorder in the elderly regardless of generalised anxiety disorder severity or level of sub-syndromal depression. The anxiolytic efficacy of pregabalin had an early onset (by 2 weeks) and significantly improved both psychic and somatic symptoms of anxiety.

Stuart Montgomery, MD, FRCPsych, Imperial College School of Medicine, University of London, UK; Krai Chatamra, PhD, Pfizer Global Research and Development, Sandwich, UK; Lynne Pauer, MS, Pfizer Global Research and Development, Ann Arbor Michigan, USA; Ed Whalen, PhD, Francesca Baldinetti, MD, Pfizer Inc, New York, New York, USA

Correspondence: Professor Stuart A. Montgomery, PO Box 8751, London W13 8WH, UK. Email: stuart@samontgomery.co.uk

First received 9 Mar 2007, final revision 19 Feb 2008, accepted 7 Mar 2008

\section{References}

1 Schoevers RA, Beekman AT, Deeg DJ, Jonker C, van Tilburg W. Comorbidity and risk-patterns of depression, generalised anxiety disorder and mixed anxiety-depression in later life: results from the AMSTEL study. Int J Geriat Psychiatry 2003; 18: 994-1001.

2 Beekman AT, Bremmer MA, Deeg DJ, van Balkom AJ, Smit JH, de Beurs E, van Dyck $R$, van Tilburg W. Anxiety disorders in later life: a report from the Longitudinal Aging Study Amsterdam. Int J Geriat Psychiatry 1998; 13: 717-26.

3 Blazer D, George LK, Hughes D. The epidemiology of anxiety disorders: an age comparison. In Anxiety in the Elderly: Treatment and Research (ed C. Salzman, B.D. Lebowitz): 17-30. Springer, 1991.

4 de Beurs E, Beekman AT, van Balkom AJ, Deeg DJ, van Dyck R, van Tilburg W. Consequences of anxiety in older persons: its effect on disability, well-being and use of health services. Psychol Med 1999; 29: 583-93.

5 Kessler RC, Zhao S, Katz SJ, Kouzis AC, Frank RG, Edlund M, Leaf P. Past-year use of outpatient services for psychiatric problems in the National Comorbidity Survey. Am J Psychiatry 1999; 156: 115-23.

6 Kessler RC, Andrade LH, Bijl RV, Offord DR, Demler OV, Stein DJ. The effects of co-morbidity on the onset and persistence of generalized anxiety disorder in the ICPE surveys. International Consortium in Psychiatric Epidemiology. Psychol Med 2002; 32: 1213-25.

7 Lieb R, Becker E, Altamura C. The epidemiology of generalized anxiety disorder in Europe. Eur Neuropsychopharmacol 2005; 15: 445-52.
8 Beekman AT, de Beurs E, van Balkom AJ, Deeg DJ, van Dyck R, van Tilburg W. Anxiety and depression in later life: co-occurrence and communality of risk factors. Am J PSychiatry 2000; 157: 89-95.

9 Bruce SE, Yonkers KA, Otto MW, Eisen JL, Weisberg RB, Pagano M, Shea MT, Keller MB. Influence of psychiatric comorbidity on recovery and recurrence in generalized anxiety disorder, social phobia, and panic disorder: a 12-year prospective study. Am J Psychiatry 2005; 162: 1179-87.

10 Schuurmans J, Comijs HC, Beekman AT, de Beurs E, Deeg DJ, Emmelkamp $\mathrm{PM}$, van Dyck R. The outcome of anxiety disorders in older people at 6-year follow-up: results from the Longitudinal Aging Study Amsterdam. Acta Psychiatr Scand 2005; 111: 420-8.

11 Flint AJ. Generalised anxiety disorder in elderly patients: epidemiology, diagnosis and treatment options. Drugs Aging 2005; 22: 101-14.

12 Lenze EJ, Mulsant BH, Shear MK, Dew MA, Miller MD, Pollock BG, Houck P, Tracey B, Reynolds CF 3rd. Efficacy and tolerability of citalopram in the treatment of late-life anxiety disorders: results from an 8-week randomized, placebo-controlled trial. Am J Psychiatry 2005; 162: 146-50.

13 Katz IR, Reynolds CF 3rd, Alexopoulos GS, Hackett D. Venlafaxine ER as a treatment for generalized anxiety disorder in older adults: pooled analysis of five randomized placebo-controlled clinical trials. J Amer Geriat Soc 2002; 50: 18-25.

14 Madhusoodanan S, Bogunovic OJ. Safety of benzodiazepines in the geriatric population. Expert Opin Drug Safe 2004; 3: 485-93.

15 Montgomery SA, Tobias K, Zornberg GL, Kasper S, Pande AC. Efficacy and safety of pregabalin in the treatment of generalized anxiety disorder: a 6week, multicenter, randomized, double-blind, placebo-controlled comparison of pregabalin and venlafaxine. J Clin Psychiatry 2006; 67: 771-82.

16 Rickels K, Pollack MH, Feltner DE, Lydiard RB, Zimbroff DL, Bielski RJ, Tobias K, Brock JD, Zornberg GL, Pande AC. Pregabalin for treatment of generalized anxiety disorder: a 4-week, multicenter, double-blind, placebo-controlled trial of pregabalin and alprazolam. Arch Gen Psychiatry 2005; 62: 1022-30.

17 Pohl RB, Feltner DE, Fieve RR, Pande AC. Efficacy of pregabalin in the treatment of generalized anxiety disorder: double-blind, placebo-controlled comparison of BID versus TID dosing. J Clin Psychopharm 2005; 25: 151-8.

18 Feltner DE, Crockatt JG, Dubovsky SJ, Cohn CK, Shrivastava RK, Targum SD, Liu-Dumaw M, Carter CM, Pande AC. A randomized, double-blind, placebocontrolled, fixed-dose, multicenter study of pregabalin in patients with generalized anxiety disorder. J Clin Psychopharm 2003; 23: 240-9.

19 International Conference on Harmonisation. Guidance for Industry. E6 Good Clinical Practice: Consolidated Guidance. US Food and Drug Administration, 1996 (http://www.fda.gov/cder/guidance/959fnl.pdf).

20 American Psychiatric Association. Diagnostic and Statistical Manual of Mental Disorders (4th edn) (DSM-IV). APA Press, 1994.

21 Sheehan DV, Lecrubier $\mathrm{Y}$, Sheehan $\mathrm{KH}$, Amorim $\mathrm{P}$, Janavs J, Weiller $\mathrm{E}_{\text {, }}$ Hergueta T, Baker R, Dunbar GC. The Mini-International Neuropsychiatric Interview (M.I.N.I.): the development and validation of a structured diagnostic psychiatric interview for DSM-IV and ICD-10. J Clin Psychiatry 1998; 59 (suppl 20): 22-33.

22 Sheehan DV, Lecrubier $\mathrm{Y}$, Sheehan $\mathrm{KH}$, Amorim P, Janavs J, Weiller $\mathrm{E}$, Hergueta T, Baker R, Dunbar GC. The validity of the Mini International Neuropsychiatric Interview (MINI) according to the SCID P and its reliability. Eur Psychiatry 1997; 12: 232-41.

23 Hamilton M. The assessment of anxiety states by rating. Br J Med Psychol 1959; 32: 10.

24 Bech JG, Stanley MA, Zebb BJ. Effectiveness of the Hamilton Anxiety Rating Scale with older Generalized Anxiety Disorder patients. J Clin Geropsychol 1999; 5: 281-90.

25 Hamilton M A. A rating scale for depression. J Neurol Neurosurg Psychiatry 1960; 23: 56-62.

26 Guy W. ECDEU Assessment Manual for Psychopharmacology. US Department of Health, Education, and Welfare, Public Health Service, Alcohol, Drug Abuse, and Mental Health Administration, National Institute of Mental Health, 1976.

27 Bech P, Allerup P, Maier W, Albus M, Lavori P, Ayuso JL. The Hamilton scales and the Hopkins Symptom Checklist (SCL-90). A cross-national validity study in patients with panic disorders. Br J Psychiatry 1992; 160: 206-11.

28 Neter J, Wasserman W, Kutner MH. Applied Linear Statistical Models. Irwin, 1990.

29 Hosmer DW, Lemeshow L. Applied Logistic Regression. John Wiley \& Sons, 1989.

30 Stokes ME, Davis CS, Koch GG. Categorical Data Analysis Using the SAS System. SAS Institute Inc, 1995.

31 Stein DJ, Andersen HF, Goodman WK. Escitalopram for the treatment of generalised anxiety disorder: efficacy across different subgroups and outcomes. Ann Clin Psychiatry 2005; 17: 71-5.

32 Thase ME. Treatment of anxiety disorders with venlafaxine XR. Expert ReV Neurother 2006; 6: 269-82. 